CZASOPISMO INŻYNIERII LA¿DOWEJ, ŚRODOWISKA I ARCHITEKTURY JOURNAL OF CIVIL ENGINEERING, ENVIRONMENT AND ARCHITECTURE

JCEEA, t. XXXIV, z. 64 (2/II/17), kwiecień-czerwiec 2017, s. 55-62, DOI: 10.7862/rb.2017.81

\author{
Sabina KSIĄŻEK ${ }^{1}$ \\ Małgorzata KIDA ${ }^{2}$ \\ Piotr KOSZELNIK ${ }^{3}$
}

\title{
MOŻLIWOŚCI KATALITYCZNEGO ZASTOSOWANIA MATERIAŁÓW ODPADOWYCH
}

\begin{abstract}
Zrównoważona chemia stanowi jedną z form działań zmierzających do zmniejszenia zanieczyszczeń środowiska i jest ważnym elementem zrównoważonego rozwoju. Zielona chemia dostarcza rozwiązań do takich globalnych wyzwań jak zmiana klimatu, zrównoważone rolnictwo, energia, zatrucie środowiska i wyczerpywanie bogactw naturalnych. Zielone technologie nie tylko chronią środowisko naturalne, ale zazwyczaj są również korzystne z punktu widzenia ekonomicznego. Podstawowym problemem dla środowiska jest znaczne zmniejszenie się zapasu surowców naturalnych. Zatem, dążenie do większej rozmaitości źródeł surowcowych to ważny obszar działania zielonej chemii. Kataliza należy do podstawowych narzędzi realizowania wszystkich zasad zielonej, zrównoważonej chemii wychodząc od badań podstawowych do zastosowań przemysłowych. Według zasad zielonej chemii, gdzie tylko jest to możliwe, powinno dążyć się do stosowania surowców odnawialnych oraz odpadów, które nie tylko zapewniają alternatywne surowce odnawialne, ale także stanowią materiał do produkcji katalizatorów. Zastosowanie materiału naturalnego jako katalizatora lub substratu do wytwarzania katalizatora powoduje nie tylko obniżenie kosztów związanych z produkcją katalizatorów, ale sprawia, że stosowany proces jest przyjazny dla środowiska. Ponadto, wykorzystanie materiałów odpadowych zmniejsza problem unieszkodliwiania odpadów. Wśród najbardziej obfitych zasobów produktów ubocznych technologii są przede wszystkim odpady z rolnictwa, górnictwa i produkcji metali, a w szczególności przemysłu hutniczego. Celem pracy jest scharakteryzowanie właściwości katalitycznych wybranych materiałów odpadowych.
\end{abstract}

Słowa kluczowe: odpady, kataliza, zielona chemia, zrównoważony rozwój

1 Autor do korespondencji / corresponding author: Sabina Książek, Politechnika Rzeszowska, Zakład Inżynierii i Chemii Środowiska, Wydział Budownictwa, Inżynierii Środowiska i Architektury, 35-959 Rzeszów, al. Powstańców Warszawy 6, tel. 178652407, s.ksiazek@prz.edu.pl

2 Małgorzata Kida, Politechnika Rzeszowska, Zakład Inżynierii i Chemii Środowiska, Wydział Budownictwa, Inżynierii Środowiska i Architektury, 35-959 Rzeszów, al. Powstańców Warszawy 6, tel. 178652407, mkida@prz.edu.pl

${ }^{3}$ Piotr Koszelnik, Politechnika Rzeszowska, Zakład Inżynierii i Chemii Środowiska, Wydział Budownictwa, Inżynierii Środowiska i Architektury, 35-959 Rzeszów, al. Powstańców Warszawy 6, tel. 178651065, 178652407, pkoszel@ prz.edu.pl 


\section{Wprowadzenie}

W związku z działalnością produkcyjną oraz z użytkowaniem różnego rodzaju wyrobów powstaje coraz więcej odpadów, których zagospodarowanie często jest jednym $\mathrm{z}$ najistotniejszych problemów ochrony środowiska. W ostatniej dekadzie XX wieku przemysł chemiczny został zmuszony do całkowitej zmiany $\mathrm{w}$ postrzeganiu procesów produkcyjnych. Miało to związek z wprowadzeniem nowego trendu skupionego na zrównoważonym rozwoju. Obecnie czyste, zrównoważone technologie stanowią podstawę wytwórstwa różnorodnych produktów i usług. Zapewniają one odpowiednio wysoką wydajność, zmniejszają koszty, znacznie redukują lub wręcz eliminują negatywny wpływ na środowisko. Zrównoważone technologie cechować powinna bezodpadowość, materiałooszczędność i energooszczędność [20]. Cele te można osiągnąć poprzez wybór surowca, który może być przetworzony w produkt $\mathrm{z}$ największą możliwą selektywnością, wybór metody zapewniającej najmniejsze możliwe zużycie energii, wybór najbardziej aktywnego i selektywnego katalizatora i wreszcie udoskonalenie procesów utylizacji i zagospodarowania produktów ubocznych, odpadów i produktów poużytkowych [15]. Ograniczanie wytwarzania odpadów to podstawowa zasada zrównoważonego użytkowania zasobów naturalnych i antropogenicznych. $\mathrm{Z}$ kolei odzysk surowców i energii z odpadów stanowi podstawowy warunek ochrony zasobów naturalnych [4]. Zgromadzone na składowiskach odpady mają znaczną wartość jako surowce wtórne. Około $25 \%$ odpadów stanowi węgiel, $35 \%$ - cynk, ołów, żelazo i inne metale, a pozostała część to m.in. iły, popioły, żużle, odpady skalne i kruszywa [7, 14]. Przykładowo, naturalne krzemiany stanowią niezwykle interesujący surowiec do syntezy katalizatorów i adsorbentów. Szeroka gama naturalnych materiałów stałych, takich jak zeolity, iły zawierających żelazo lub miedź, minerały zawierające tlenki żelaza znalazły zastosowanie jako efektywne katalizatory w procesie utleniania związków organicznych. Odpady z przemysłu metalurgicznego, galwanizacyjnego, samochodowego oraz z produkcji aluminium, osady potechnologiczne pochodzące ze stacji uzdatniania wody, ze względu na dużą zawartość metali (żelazo, miedź, mangan, cynk) również mogą stanowić katalizatory reakcji utleniania.

W pracy zaprezentowano przykłady zastosowania materiałów naturalnych i odpadowych w reakcjach katalitycznych i w przyjaznych dla środowiska technologiach.

\section{Kataliza w zrównoważonej chemii}

Na przestrzeni ostatnich lat wzrosło zainteresowanie tzw. "zrównoważoną chemią", czyli chemią ekologiczną i przyjazną dla środowiska. Praktycznie oznacza to, że wykształciło się nowe podejście do zagadnienia syntezy, przeróbki i wykorzystania substancji chemicznych, związane ze zmniejszeniem zagrożenia dla zdrowia człowieka i środowiska [9]. Pojęcie zrównoważonej chemii 
powstało na przełomie XX i XXI wieku po opublikowaniu w 1987 r. raportu „Nasza Wspólna Ziemia” prezentującego nową koncepcję ,zrównoważonego rozwoju". W 2000 roku Organizacja Współpracy Gospodarczej i Rozwoju zdefiniowała pojęcie ,zrównoważonej chemii” jako rozwinięcie pojęcia „,zrównoważonego rozwoju". Oznacza ono projektowanie, wytwarzanie i wykorzystywanie $w$ technologiach chemicznych produktów pozwalających na osiąganie dużych korzyści ekonomicznych i jednocześnie przyjaznych środowisku. W trakcie projektowania i prowadzenia procesów chemicznych należy zmniejszać ilość zużywanej energii, surowców nieodnawialnych i wody. Koncepcja „zrównoważonej chemii" nakazuje również redukować ilość wytwarzanych zanieczyszczeń i odpadów na każdym etapie produkcji oraz produkować takie produkty chemiczne, które mogą być użyte ponownie lub poddane recyklingowi [6]. Ważnym obszarem działań w ramach zrównoważonej chemii jest poszukiwanie nowych sposobów przyspieszania i katalizy procesów chemicznych. Kataliza odgrywa niezwykle istotną rolę w zapobieganiu i usuwaniu skutków zanieczyszczeń środowiska naturalnego. Rola ta przejawia się zarówno w zakresie badań podstawowych, jak i w zastosowaniach przemysłowych. Reakcje katalityczne powodują zwykle zmniejszenie zapotrzebowania energii i zwiększenie selektywności. Takie reakcje wymagają zmniejszonej liczby reagentów, a te ostatnie mogą być surowcami odnawialnymi [12]. Kataliza i procesy katalityczne stanowią podstawę nowoczesnego przemysłu chemicznego, petrochemicznego i farmaceutycznego. Stanowią również istotne ogniwo w walce z eliminacją szkodliwych i niebezpiecznych odpadów, przez co zapobiegają zanieczyszczeniom środowiska [5].

\section{Przykłady katalitycznych zastosowań materiałów naturalnych i odpadowych}

W ostatnich latach wzrasta ilość doniesień literaturowych dotyczących sposobu wytwarzania katalizatorów heterogenicznych z materiałów odpadowych (naturalnych i przemysłowych). Zwiększonym zainteresowaniem cieszą się produkty uboczne procesów technologicznych, które mogą stać się potencjalnymi materiałami o rozszerzonej funkcjonalności. To zainteresowanie wynika głównie z aspektu ekonomicznego i środowiskowego. Materiały odpadowe często stanowią cenne surowce do produkcji katalizatorów lub same stanowią aktywne katalizatory. Dodatkowo, wykorzystanie materiałów odpadowych zmniejsza problem unieszkodliwiania odpadów, przez co wpisuje się w zakres zrównoważonego rozwoju i zielonej chemii. Wśród najbardziej obfitych zasobów produktów ubocznych technologii są przede wszystkim odpady $\mathrm{z}$ rolnictwa, górnictwa i produkcji metali, a w szczególności przemysłu hutniczego [3]. W tabeli 1 i 2 przedstawiono przykładowe materiały odpadowe posiadające właściwości katalityczne oraz ich zastosowanie w reakcjach chemicznych. 
Tabela 1. Przykłady materiałów odpadowych o właściwościach katalitycznych

Table 1. Examples of waste materials having a catalytic properties

\begin{tabular}{|c|c|c|}
\hline Materiał odpadowy & Wielkość produkcji & Literatura \\
\hline Czerwony szlam & $>70$ mln ton rocznie w skali światowej & {$[13]$} \\
\hline Żużel aluminiowy & 5 mln ton rocznie w skali światowej & {$[2]$} \\
\hline Popiół lotny & 430 mln ton w skali światowej (2003 rok) & {$[17]$} \\
\hline Żużel żelazowy & $240-290$ mln w skali światowej (2008 rok) & {$[11]$} \\
\hline Skorupki jaj kurzych & 4 mln ton rocznie (Chiny) & {$[18]$} \\
\hline Łuski ryżu & 70 mln rocznie w skali światowej & {$[2]$} \\
\hline
\end{tabular}

Przykładem poprodukcyjnego materiału odpadowego jest czerwony szlam. Jest on produktem ubocznym w procesie Bayera, czyli powstaje podczas produkcji aluminium. Roczna ilość tego rodzaju odpadu stale rośnie, ze względu na rosnące światowe zapotrzebowanie na aluminium. O właściwościach katalitycznych tego materiału decyduje stosunkowo duża zawartość żelaza, która nadaje szeroką gamę ciekawych katalitycznych właściwości. Czerwony szlam znalazł zastosowano m.in. bezpośrednio jako składnik aktywny, np. w produkcji $\mathrm{H}_{2}$ i ketonizacji, w reakcjach utleniania, uwodornienia lub też jako nośnik wielu katalizatorów [2].

Tabela 2. Przykłady zastosowania materiałów odpadowych

Table 2. Examples of the uses of waste materials

\begin{tabular}{|c|c|c|c|}
\hline $\begin{array}{c}\text { Materiał } \\
\text { odpadowy }\end{array}$ & $\begin{array}{c}\text { Składnik } \\
\text { aktywny }\end{array}$ & Zastosowanie & Literatura \\
\hline \multirow{4}{*}{ Żużel } & $\mathrm{SiO}_{2}$ & $\begin{array}{r}\text { Utlenianie CO i lotnych związków } \\
\text { organicznych }\end{array}$ & \\
\cline { 2 - 3 } & $\mathrm{TiO}_{2}$ & Denitryfikacja & \\
\cline { 2 - 3 } & $\mathrm{MgO}-\mathrm{CaO} / \mathrm{SiO}_{2}$ & Transestryfikacja & \\
\hline \multirow{2}{*}{ Czerwony szlam } & $\mathrm{Fe}$ & Produkcja $\mathrm{H}_{2}$ & \\
\cline { 2 - 3 } & $\mathrm{Fe}_{2} \mathrm{O}_{3}$ & Ketonizacja & \\
\hline \multirow{3}{*}{ Popiół lotny } & $\mathrm{CaO}$ & Transestryfikacja & \\
\cline { 2 - 3 } & $\mathrm{V}_{2} \mathrm{O}_{5}$ & Utlenianie toluenu \\
\cline { 2 - 3 } & $\mathrm{Cu}$ & Hydrogenoliza glicerolu & \\
\hline
\end{tabular}

Badania zespołu Teixeira potwierdziły możliwość wykorzystania czerwonego szlamu jako źródła aktywnego katalizatora konwersji gazu ziemnego, mieszaniny metanu i innych węglowodorów (rys. 1) [16]. 


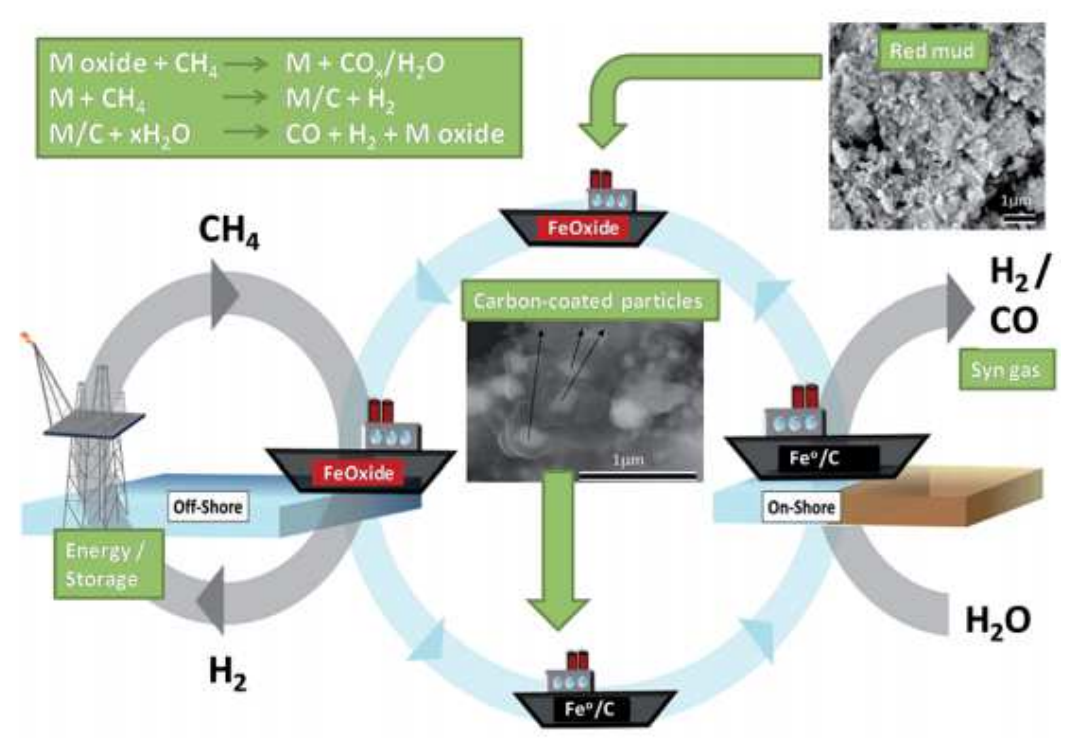

Rys. 1. Schemat procesu depozycji węgla i konwersji gazu ziemnego w obecności czerwonego szlamu, opracowano na podstawie [3]

Fig. 1. Diagram of the process of deposition of coal and conversion of natural gas in the presence of red mud, based on [3]

Kolejnym przemysłowym produktem ubocznym jest popiół lotny, który jest drobnoziarnistą frakcją cząstek powstających podczas spalania paliw. Składowanie odpadów ze spalania węgli jest szczególnie uciążliwe i kosztowne, głównie ze względu na niezbędne zabezpieczenia zapobiegające wywiewaniu pyłu i izolację gruntów. Produkcję samego popiołu lotnego, który stanowi największy procent wszystkich ubocznych produktów spalania węgla (ok. 50-70\%) [10], w USA i Unii Europejskiej średnio ocenia się na ponad $100 \mathrm{mln}$ ton rocznie, gdzie $60 \%$ tych odpadów jest składowane. Skład popiołów jest uzależniony od rodzaju spalanych materiałów i zastosowanej technologii. Głównie zawiera $\mathrm{Al}_{2} \mathrm{O}_{3}$ i $\mathrm{SiO}_{2}$ oraz dodatki, takie jak $\mathrm{Fe}_{2} \mathrm{O}_{3}, \mathrm{CaO}, \mathrm{MgO}, \mathrm{K}_{2} \mathrm{O}$ i $\mathrm{Na}_{2} \mathrm{O}[18,19]$. $\mathrm{W}$ trakcie poszukiwania nowych kierunków wykorzystania popiołów lotnych, stwierdzono podobieństwo ich składu chemicznego i mineralnego do niektórych materiałów naturalnych (m.in. zeolitów). Na podstawie tych obserwacji zapoczątkowane zostały prace dotyczące syntezy zeolitów i innych glinokrzemianów z popiołów lotnych [8]. Zeolity są mikroporowatymi, uwodnionymi glinokrzemianami pierwiastków alkalicznych, ziem alkalicznych lub innych kationów, które w swojej strukturze krystalicznej zawierają liczne kanały i komory o różnych rozmiarach nadające im szereg charakterystycznych właściwości sorpcyjnych, jonowymiennych, molekularno-sitowych oraz katalitycznych. Materiały porowate mają rozpowszechnione zastosowanie (katalizatory, nośniki katalizatorów) ze względu na ich wysoką odporność termiczną, hydrotermalną, mecha- 
niczną i chemiczną. Do najważniejszych zeolitów tworzących złoża należą klinoptylolit, filipsyt, chabazyt i mordenit. $Z$ danych literaturowych wynika, iż z każdego rodzaju popiołów, stosując odpowiednią metodologię prac laboratoryjnych, można otrzymać różne struktury zeolitowe m.in.: analcym, chabazyt, kankrynit, NaP1, ZSM-5, ZMS-28, Na-X, Na-Y, filipsyt, sodalit [1]. W ostatnim czasie pojawiło się również wiele badań naukowych dotyczących wykorzystania materiałów naturalnych, np. muszli małż, ślimaków, żółwi i skorupek jaj kurzych, łusek ryżu, materiałów ilastych, minerałów, gleb bogatych w metale, itp. do wytwarzania katalizatorów transestryfikacji i utleniania związków organicznych w procesie Fentona. Przykładowo, muszle w wyniku kalcynacji w wysokiej temperaturze przekształcają się w materiał bogaty w $\mathrm{CaO}$ (w wyniku rozkładu $\mathrm{CaCO}_{3}$ ). Katalizatory oparte na tlenku wapnia są obecnie przedmiotem zainteresowań wielu badaczy zajmujących się produkcją biodiesla [2]. Rysunek 2 przedstawia proponowany sposób syntezy katalizatora transestryfikacji $\mathrm{z}$ muszli małż.

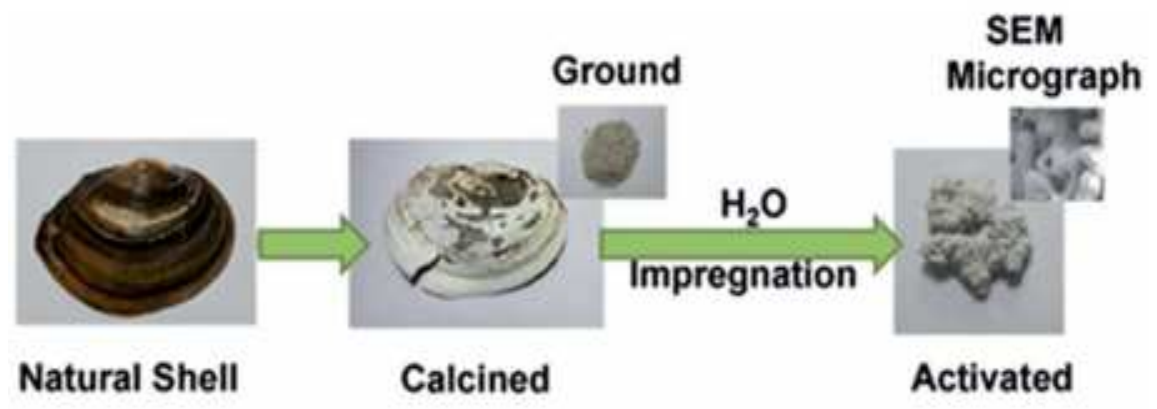

Rys. 2. Etapy wytwarzania katalizatora transestryfikacji z muszli małż, opracowano na podstawie [3]

Fig. 2. Manufacturing steps of a transesterification catalyst from mussel shells, based on [3]

\section{Podsumowanie}

W niniejszej pracy przedstawiono przykłady wykorzystania materiałów odpadowych w katalizie. Odpady można ogólnie podzielić na przemysłowe (np. czerwony szlam, żużel aluminium, osady po odżelazianiu wody) oraz te, które pochodzą ze źródeł naturalnych (np. skorupki jaj, łuski ryżu, zeolity, minerały). W niektórych przypadkach, materiały te mogą być bezpośrednio stosowane jako katalizatory, podczas gdy w innych, stosuje się je jako składniki, z których można wytwarzać materiały posiadające właściwości katalityczne. Oprócz generowania aktywnych, selektywnych i stabilnych katalizatorów, surowce wykorzystywane do ich produkcji powinny być bezpieczne do gromadzenia, a ich przetworzenie nie powinno generować nowych szkodliwych produktów ubocznych. 


\section{Literatura}

[1] Anielak A.M.: Właściwości fizykochemiczne klinoptylolitu modyfikowanego ditlenkiem manganu, Przemysł Chemiczny, 85, 7, 2006, s. 487-491.

[2] Balakrishnan M., Batra V.S., Hargreaves J.S.J., Pulford I.D.: Waste materialscatalytic opportunities: an overview of the application of large scale waste materials as resources for catalytic applications, Green Chemistry, vol. 13, no. 1, 2011, pp. 16-24.

[3] Bennett J.A., Wilson K., Lee A.F.: Catalytic applications of waste derived materials, Journal of Materials Chemistry A, vol. 4, no. 10, pp. 3617-3637.

[4] Borowski G.: Produkty odpadowe jako surowce wtórne, Inżynieria ekologiczna, 21, 2009, s. 85-95.

[5] Burczyk B.: Zielona chemia: zadania, cele, przykłady osiągnięć, Wiadomości Chemiczne, 56, 2002, s. 709-770.

[6] Burdyński M.: Zrównoważona chemia. Laborant, 3, 2011, s. 9-11.

[7] Dębska B., Górska K.: Ocena możliwości zagospodarowania odpadów w sektorze budowlanym. Czasopismo Inżynierii Lądowej, Środowiska i Architektury - Journal of Civil Engineering, Environment And Architecture, JCEEA, 63, 3, 2016, s. 67-74.

[8] Franus W., Wdowin M.: Wykorzystanie popiołów lotnych klasy F do produkcji materiału zeolitowego na skalę półtechniczną, Polityka Energetyczna, 20, 2, 2011, s. 79-91.

[9] Górka K.: Ekonomiczne aspekty ochrony środowiska naturalnego, Problemy Ekologii, 21, 1997, s. 2-9.

[10] Klojzy-Karczmarczyk B.: Zastosowanie odpadów energetycznych w ograniczaniu transportu zanieczyszczeń ze składowisk odpadów górniczych, Studia, Rozprawy, Monografie, 2003, s. 117-113.

[11] Kuwahara Y., Ohmichi T., Kamegawa T., Mori K., Yamashita H.: A novel conversion process for waste slag: synthesis of a hydrotalcite-like compound and zeolite from blast furnace slag and evaluation of adsorption capacities. Journal of Materials Chemistry, vol. 20, no. 24, 2010, pp. 5052-5062.

[12] Paryjczak T., Lewicki A.: Zielona chemia. Wybrane zagadnienia, Przemysł Chemiczny, 82, 2003, s. 525-531.

[13] Pontikes Y., Rathossi C., Nikolopulos P., Angelopoulos G.N., Jayaseelan D., Lee W.E.: Effect of firing temperature and atmosphere on sintering of ceramics made from Bayer process bauxite residue. Ceramics international, vol. 35, no. 1, 2009, pp. 401-407.

[14] Rosik-Dulewska C.: Podstawy gospodarki odpadami, Wydawnictwo Naukowe PWN, Warszawa 2015.

[15] Taniewski M.: Rola chemii i przemysłu chemicznego w rozwoju technicznym i gospodarczym świata na przełomie XX i XXI wieku, Przemysł Chemiczny, 72, 7 , 1993, s. 263-266.

[16] Teixeira I.F., Medeiros T.P., Freitas P.E., Rosmaninho M.G., Ardisson J.D., Lago R.M.: Carbon deposition and oxidation using the waste red mud: A route to store, 
transport and use offshore gas lost in petroleum exploration, Fuel, vol. 124, 2014, pp. 7-13.

[17] Wang S.: Application of solid ash based catalysts in heterogeneous catalysis, Environmental science \& technology, vol. 42, no. 19, 2008, pp. 7055-7063.

[18] Wei Z., Xu C., Li B.: Application of waste eggshell as low-cost solid catalyst for biodiesel production, Bioresource technology, vol. 100, no. 11, 2009, pp. 28832885.

[19] Xuan X., Yue C., Li S., Yao Q.: Selective catalytic reduction of NO by ammonia with fly ash catalyst. Fuel, vol. 82, no. 5, 2003, pp. 575-579.

[20] Zdyb A.: Wybrane możliwości zastosowania nanostruktur w inżynierii środowiska, Czasopismo Inżynierii Lądowej, Środowiska i Architektury - Journal of Civil Engineering, Environment And Architecture, JCEEA, z. 62, 2, 2015, s. 611-617. DOI: $10.7862 /$ rb.2015.90.

\section{POSSIBILITIES OF THE CATALYTIC APPLICATION OF WASTE MATERIALS}

\section{S u m m a r y}

Sustainable chemistry is one of the forms of action to reduce pollution of the environment and it is an important element of sustainable development. Green chemistry provides solutions to such global challenges as climate change, sustainable agriculture, energy, toxics in the environment and the depletion of natural resources. Green technology will not only protect the environment, but they are usually also preferable from the economic point of view. The main concern for the environment is a significant reduction in the supply of natural materials. Therefore, the pursuit of a greater variety of sources of natural materials is an important area of activity of green chemistry. Catalysis is one of the basic tools of implementation of all principles of green, sustainable chemistry, from basic research to industrial applications. According to the seventh principle of green chemistry, where possible, should seek to use renewable raw materials and waste, which not only provide alternative renewable raw materials, but also provide the material for the production of catalysts. The use of natural material or waste material as catalyst or a substrate for the preparation of the catalyst will not only reduce the costs associated with the production of catalysts, but makes the used process is environmentally friendly. Waste materials also are valuable materials for the production of catalysts or are themselves active catalysts. In addition, the use of waste materials reduces the problem of waste disposal. Among the most abundant resources of technology products are primarily agricultural, mining and metals, and in particular the steel industry. The aim of the work is to characterize the catalytic properties of selected waste materials.

Keywords: waste, catalysis, green chemistry, sustainable development

Przestano do redakcji: 1.02 .2017 r.

Przyjęto do druku: $30.06 .2017 \mathrm{r}$. 